\title{
Effect of Payment Incentives on Cancer Screening in Ontario Primary Care
}

\author{
Tara Kiran, $M D, M S c^{1-3}$ \\ Andrew S. Wilton, MSc ${ }^{4}$ \\ Rabim Moineddin, $\mathrm{PbD}^{3-5}$ \\ Lawrence Paszat, MD, MSc ${ }^{4}$ \\ Richard H. Glazier, MD, MPH ${ }^{1-5}$ \\ ${ }^{1}$ Keenan Research Centre in the Li Ka \\ Shing Knowledge Institute of St. Michael's \\ Hospital, Toronto, Ontario, Canada \\ ${ }^{2}$ Department of Family and Community \\ Medicine, St. Michael's Hospital, Toronto, \\ Ontario, Canada \\ ${ }^{3}$ Department of Family and Community \\ Medicine, University of Toronto, Ontario, \\ Canada \\ ${ }^{4}$ Institute for Clinical Evaluative Sciences, \\ Toronto, Ontario, Canada \\ ${ }^{5}$ Dalla Lana School of Public Health, \\ Toronto, Ontario, Canada
}

Conflicts of interest: authors report none.

\section{CORRESPONDING AUTHOR}

Tara Kiran, MD, MSc

30 Bond St

Toronto, Ontario, Canada M5B 1W8

tara.kiran@utoronto.ca

\begin{abstract}
PURPOSE There is limited evidence for the effectiveness of pay for performance despite its widespread use. We assessed whether the introduction of a pay-forperformance scheme for primary care physicians in Ontario, Canada, was associated with increased cancer screening rates and determined the amounts paid to physicians as part of the program.
\end{abstract}

METHODS We performed a longitudinal analysis using administrative data to determine cancer screening rates and incentive costs in each fiscal year from $1999 / 2000$ to $2009 / 2010$. We used a segmented linear regression analysis to assess whether there was a step change or change in screening rate trends after incentives were introduced in 2006/2007. We included all Ontarians eligible for cervical, breast, and colorectal cancer screening.

RESULTS We found no significant step change in the screening rate for any of the 3 cancers the year after incentives were introduced. Colon cancer screening was increasing at a rate of $3.0 \%(95 \% \mathrm{Cl}, 2.3 \%$ to $3.7 \%)$ per year before the incentives were introduced and $4.7 \%(95 \% \mathrm{Cl}, 3.7 \%$ to $5.7 \%)$ per year after. The cervical and breast cancer screening rates did not change significantly from year to year before or after the incentives were introduced. Between 2006/2007 and 2009/2010, $\$ 28.3$ million, $\$ 31.3$ million, and $\$ 50.0$ million were spent on financial incentives for cervical, breast, and colorectal cancer screening, respectively.

CONCLUSIONS The pay-for-performance scheme was associated with little or no improvement in screening rates despite substantial expenditure. Policy makers should consider other strategies for improving rates of cancer screening.

Ann Fam Med 2014;317-323. doi: 10.1370/afm.1664.

\section{INTRODUCTION}

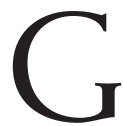
overnments around the world are trying to align physician financial incentives with desired health system goals. In the United States, the National Commission on Physician Payment Reform recently stated that "[o]ur nation cannot control runaway medical spending without fundamentally changing how physicians are paid." Over the last decade, pay for performance has been seen by many as the most promising approach to reducing health system cost and improving quality. ${ }^{2}$ Critics have questioned whether pay for performance can deliver on its promise, however, citing issues with measurement, target-setting, non-financial barriers to optimizing care, and intrinsic physician motivation..$^{3-5}$

Reducing morbidity and mortality through cancer screening is an important component of primary care. Screening for cervical cancer ${ }^{6}$ and colorectal cancer ${ }^{7}$ is generally regarded as cost-effective. Screening for breast cancer via mammography is more controversial ${ }_{1}^{8-10}$ but is still widely recommended by clinical practice guidelines. ${ }^{11,12}$ Nevertheless, a substantial proportion of individuals do not receive recommended cancer screening. ${ }^{13-16}$ It is unclear whether pay for performance can shrink gaps in preventive care specifically ${ }^{17,}{ }^{18}$ or primary care more generally. ${ }^{19}$

We evaluated a large-scale pay-for-performance scheme introduced in Ontario in 2006 and aimed at improving cancer screening in primary care. 


\section{METHODS}

\section{Setting}

Ontario is Canada's largest province, with a population of approximately 12.8 million people in 2011. Physician visits and cancer screening tests are paid for by the Ontario Health Insurance Plan (OHIP), with no outof-pocket payments, for all permanent residents in the province.

Between 2002 and 2010, approximately 75\% of Ontario residents joined patient-centered medical homes. ${ }^{20}$ Key features of the medical homes include patient enrollment, after-hours coverage, and physician payment reform including the introduction of capitation payments (ranging from $20 \%$ to $75 \%$ of physician income) and financial incentives, including ones for preventive health care. ${ }^{21}$ Approximately $10 \%$ of Ontarians see a primary care physician who does not practice in a medical home and is paid fee-for-service. The remaining $15 \%$ either do not have a regular primary care physician or visit a primary care physician who practices in a medical home in which they are not formally enrolled.

\section{Study Design}

\section{Cross-Sectional Analysis}

We assessed patient characteristics associated with cervical, breast, and colorectal cancer screening as well as use of the preventive care incentives among all eligible primary care physicians from April 1, 2009 to March 31,2010 . Physicians were excluded from the analysis if they were in their first year of practice or had enrolled fewer than 100 patients.

\section{Longitudinal Analysis}

We calculated age- and sex-standardized screening rates for cervical, breast, and colorectal cancer in each fiscal year from 1999-2000 to 2009-2010 and the amount of money spent on preventive care incentives each fiscal year after the pay-for-performance program was introduced broadly on April 1, 2006. Because of limited data availability in the earliest years of this period, we assessed colorectal cancer screening rates (fecal occult blood testing or colonoscopy) only for the years from 2001-2002 to 2009-2010. We stratified cancer screening rates by neighborhood income quintile and by whether the individual was enrolled with a physician who practiced in a medical home.

We used administrative claims data accessed through a comprehensive research agreement between the Institute for Clinical Evaluative Sciences and the Ontario Ministry of Health and Long-Term Care (MOHLTC). Before data analysis, patient and provider identifiers were replaced with unique encrypted numbers. This study was approved by the Research Ethics Board of Sunnybrook Research Institute in Toronto, Ontario.

\section{Cancer Screening}

We calculated cancer screening rates using claims submitted to OHIP. We determined whether individuals were due for screening based on their ages and timelines indicated by the preventive care incentives, which specify a 30 -month window for screening (Table 1 ). For cervical cancer screening rates, we determined the proportion of women aged 35 to 69 years who received a Papanicolaou (Pap) smear screening in the 30 months before the end of the relevant fiscal year, excluding those who had had a hysterectomy. For breast cancer screening rates, we determined the proportion of women aged 50 to 69 years who received a mammogram in the 30 months before the end of the relevant fiscal year, excluding those who had had a mastectomy or were being treated for breast cancer. And for colorectal cancer screening rates, we determined the proportion of adults aged 50 to 74 years who either received fecal occult blood testing (FOBT) in the 30 months before the end of the relevant fiscal year or had had a colonoscopy in the previous 10 years, excluding those with a history of colon cancer.

\section{Preventive Care Incentives}

We assessed use of the incentives for cervical, breast, and colorectal cancer screening using claims submitted to OHIP. Incentives for all 3 types of screening were introduced broadly in 2006-2007, with more incentives for colorectal cancer screening added in 2008-2009.

The incentive program allowed primary care physicians in patient-centered medical homes to bill 1 incentive code annually for each type of screening based on their own calculation of targets achieved (Table 1). In 2009-2010, physicians could receive a maximum of $\$ 8,400$ if they met the highest targets for all 3 types of screening-about $3 \%$ of their gross income. ${ }^{22}$

\section{Other Data Sources}

Patient age, sex, and place of residence were obtained from the registry of people covered by OHIP. We derived neighborhood income by linking census data to the patients' residential postal codes and stratified income into quintiles. For the longitudinal analysis, income quintile was calculated for patients for each fiscal year. Patient diagnoses were derived from physician billing claims submitted to OHIP and the hospitalization data collected by Discharge Abstract Database from the Canadian Institute for Health Information. We used the Johns Hopkins ACG software to assign patients to Resources Utilization Bands based on similar expected health care utilization $(1=$ low, $5=$ high $){ }^{23}$

Enrollment tables provided by the MOHLTC identified patients enrolled with physicians practicing in patient-centered medical homes as of 2009. The stratified longitudinal analysis followed these patients back 
in time, excluding them from the analysis for years when they were not eligible for screening.

We determined the amounts paid to physicians under the incentive program by multiplying the number of times each preventive care incentive code was billed by the financial value of the fee code. In addition to the codes described in Table 1, we included codes introduced at the time of the incentive program such as ones that reimbursed physicians for contacting patients to remind them that they were due for screening (see Supplemental Appendix). We did not include payments to physicians for conducting screening tests.

\section{Statistical Analysis}

We used segmented linear regression models to assess the change in age- and sex-standardized screening rates after 2006-2007, when the largest increase in billing of the screening incentive occurred. Models allowed 1 linear trend before the intervention (from the start of the study period to 2005-2006), a step change between 2005-2006 and the year of the intervention (2006-2007), and a different linear trend after the intervention (from 2006-2007 to 2009-2010). ${ }^{24}$ Segmented linear regression is a practical way to assess the impact of a health policy change. ${ }^{25}$

We used a Chow test to confirm that there was a structural break in the screening data between 2005 2006 and 2006-2007. We also performed a DurbinWatson test to determine the presence of first-order and second-order autocorrelation in each of the 3 data series. We detected no significant autocorrelation, so we assumed independence of the cancer screening observations when performing the regression analysis.

\section{RESULTS}

The characteristics of Ontarians eligible for and receiving screening in 2009-2010 are described in Table 2.

In $2009-2010,84 \%(4,992)$ of eligible physicians billed at least 1 of the 3 cancer screening incentive codes and $22 \%(1,278)$ billed the highest payment category for all 3 cancer screening incentives.

During the study period, the age-adjusted screening rate increased from $55 \%$ to $57 \%$ for cervical cancer, $60 \%$ to $63 \%$ for breast cancer, and $20 \%$ to $51 \%$ for colorectal cancer (Figure 1). There was no significant step change in the screening rate for any of the 3 cancers in the year immediately after the incentives were introduced (Table 3). Colon cancer screening was increasing at a rate of $3.0 \%(95 \% \mathrm{CI}, 2.3 \%$ to $3.7 \%)$ per year before the incentives were introduced and $4.7 \%$ (95\% CI, 3.7\% to $5.7 \%$ ) per year after. The cervical and breast cancer screening rates did not change significantly from year to year before or after the incentives were introduced. Between 2006-2007 and 2009-2010, a total of $\$ 28.3$ million, $\$ 31.3$ million, and $\$ 50.0$ million in incentive payments was paid to physicians for cervical, breast, and colorectal cancer screening, respectively.

\section{Table 1. Description of Financial Incentives for Cancer Screening Introduced for Primary Care Physicians} in Ontario in 2006-2007

\begin{tabular}{|c|c|c|c|c|c|}
\hline $\begin{array}{l}\text { Cancer } \\
\text { Screening }\end{array}$ & $\begin{array}{l}\text { Patients Included in } \\
\text { Incentive Calculation }\end{array}$ & $\begin{array}{l}\text { Patients Excluded From } \\
\text { Incentive Calculation }\end{array}$ & $\begin{array}{l}\text { Fee } \\
\text { Codes }\end{array}$ & $\begin{array}{c}\text { Self-reported } \\
\text { Target Achieved, \% }\end{array}$ & $\begin{array}{l}\text { Financial } \\
\text { Value, \$ }\end{array}$ \\
\hline \multirow[t]{5}{*}{ Cervical } & \multirow{5}{*}{$\begin{array}{l}\text { Enrolled women aged } 35 \text { to } 69 \mathrm{y}^{\mathrm{b}} \\
\text { who had received a Papanicolaou } \\
\text { test in the previous } 30 \text { mo }\end{array}$} & \multirow{5}{*}{$\begin{array}{l}\text { Women who had undergone } \\
\text { hysterectomy }\end{array}$} & Q105 & 60 & 220 \\
\hline & & & Q106 & 65 & 440 \\
\hline & & & Q107 & 70 & 660 \\
\hline & & & Q108 & 75 & 1,320 \\
\hline & & & Q109 & 80 & 2,200 \\
\hline \multirow[t]{5}{*}{ Breast } & \multirow{5}{*}{$\begin{array}{l}\text { Enrolled women aged } 50 \text { to } 69 \mathrm{y}^{\mathrm{b}} \\
\text { who had received a mammogram } \\
\text { in the previous } 30 \text { mo }\end{array}$} & \multirow{5}{*}{$\begin{array}{l}\text { Women who had had a mastec- } \\
\text { tomy or were being treated } \\
\text { for breast cancer }\end{array}$} & Q110 & 55 & 220 \\
\hline & & & Q111 & 60 & 440 \\
\hline & & & Q112 & 65 & 770 \\
\hline & & & Q113 & 70 & 1,320 \\
\hline & & & Q114 & 75 & 2,200 \\
\hline \multirow[t]{6}{*}{ Colorectal } & \multirow{6}{*}{$\begin{array}{l}\text { Enrolled adults aged } 50 \text { to } 74 \mathrm{y}^{\mathrm{b}} \\
\text { who had received a fecal occult } \\
\text { blood test in the previous } 30 \text { mo }\end{array}$} & \multirow{6}{*}{$\begin{array}{l}\text { Adults who had colon cancer, } \\
\text { IBD, or malignant bowel dis- } \\
\text { ease or had undergone colo- } \\
\text { noscopy in the previous } 10 \text { y }\end{array}$} & Q118 & 15 & 220 \\
\hline & & & Q119 & 20 & 440 \\
\hline & & & Q120 & 40 & 1,100 \\
\hline & & & Q121 & 50 & 2,200 \\
\hline & & & $\mathrm{Q} 122^{\mathrm{C}}$ & 60 & 3,300 \\
\hline & & & Q123c & 70 & 4,000 \\
\hline \multicolumn{6}{|c|}{$\mathrm{IBD}=$ inflammatory bowel disease. } \\
\hline \multicolumn{6}{|c|}{ 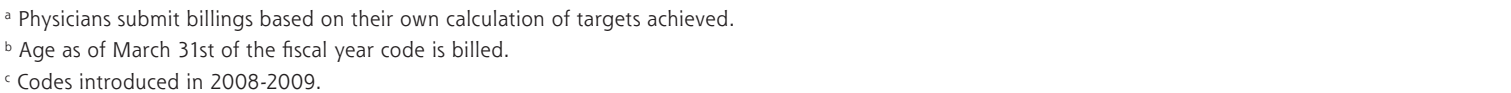 } \\
\hline
\end{tabular}


Table 2. Characteristics of Ontarians Eligible for and Receiving Cervical, Breast, and Colorectal Cancer Screening in the 30 Months Before March 31, 2010

\begin{tabular}{|c|c|c|c|c|c|c|}
\hline \multirow[b]{2}{*}{ Characteristic } & \multicolumn{2}{|c|}{ Cervical Cancer } & \multicolumn{2}{|c|}{ Breast Cancer } & \multicolumn{2}{|c|}{ Colorectal Cancer } \\
\hline & $\begin{array}{l}\text { Eligible for } \\
\text { Screening } \\
\text { No. }\end{array}$ & $\begin{array}{c}\text { Receiving } \\
\text { Screening } \\
\%\end{array}$ & $\begin{array}{l}\text { Eligible for } \\
\text { Screening } \\
\text { No. }\end{array}$ & $\begin{array}{c}\text { Receiving } \\
\text { Screening } \\
\%\end{array}$ & $\begin{array}{l}\text { Eligible for } \\
\text { Screening } \\
\text { No. }\end{array}$ & $\begin{array}{c}\text { Receiving } \\
\text { Screening } \\
\%\end{array}$ \\
\hline All & $3,056,337$ & 57.0 & $1,600,645$ & 62.3 & $3,713,963$ & 50.9 \\
\hline \multicolumn{7}{|l|}{ Sex } \\
\hline Female & $3,056,337$ & 57.0 & $1,600,645$ & 62.3 & $1,885,988$ & 53.8 \\
\hline Male & & & & & $1,827,975$ & 47.8 \\
\hline \multicolumn{7}{|l|}{ Age, y } \\
\hline $35-39$ & 513,044 & 60.6 & & & & \\
\hline $40-44$ & 527,937 & 59.5 & & & & \\
\hline $45-49$ & 554,117 & 59.9 & & & & \\
\hline $50-54$ & 479,207 & 59.1 & 534,558 & 56.6 & $1,088,421$ & 39.7 \\
\hline $55-59$ & 405,701 & 55.3 & 451,136 & 63.9 & 913,044 & 50.3 \\
\hline $60-64$ & 355,784 & 50.5 & 384,723 & 66.7 & 781,940 & 56.1 \\
\hline $65-69$ & 220,547 & 44.6 & 230,228 & 67.2 & 568,175 & 59.9 \\
\hline $70-74$ & & & & & 362,383 & 60.4 \\
\hline \multicolumn{7}{|l|}{ Income quintile } \\
\hline Missing & 45,676 & 20.0 & 18,552 & 25.8 & 45,212 & 25.4 \\
\hline Q1 (lowest) & 554,378 & 47.9 & 283,930 & 55.1 & 664,969 & 43.5 \\
\hline Q2 & 579,454 & 54.0 & 307,993 & 60.7 & 714,839 & 48.5 \\
\hline Q3 & 594,351 & 58.5 & 309,868 & 63.7 & 716,872 & 51.2 \\
\hline Q4 & 635,142 & 62.1 & 329,077 & 66.2 & 761,444 & 54.05 \\
\hline Q5 (highest) & 647,336 & 63.8 & 351,225 & 67.9 & 810,627 & 57.2 \\
\hline \multicolumn{7}{|c|}{ Resource Utilization Band } \\
\hline 0 (no utilization) & 451,310 & 3.5 & 183,462 & 4.8 & 487,843 & 5.6 \\
\hline 1 & 113,116 & 54.0 & 43,829 & 47.9 & 103,253 & 34.7 \\
\hline 2 & 400,656 & 58.2 & 181,700 & 56.2 & 431,944 & 42.7 \\
\hline 3 & $1,575,521$ & 68.6 & 898,747 & 71.0 & $1,960,256$ & 59.6 \\
\hline 4 & 412,256 & 71.6 & 213,565 & 73.5 & 498,735 & 65.7 \\
\hline 5 (high utilization) & 103,436 & 55.0 & 79,333 & 66.0 & 231,898 & 62.5 \\
\hline \multicolumn{7}{|c|}{ Medical home enrollment } \\
\hline Enrolled & $2,131,774$ & 66.8 & $1,160,502$ & 71.1 & $2,626,302$ & 59.5 \\
\hline Other & 924,563 & 34.4 & 440,143 & 40.1 & $1,087,661$ & 36.0 \\
\hline \multicolumn{7}{|l|}{ Comorbidities } \\
\hline Diabetes & 263,512 & 53.5 & 212,612 & 66.2 & 609,372 & 57.2 \\
\hline Hypertension & 662,545 & 57.5 & 571,053 & 69.9 & $1,470,212$ & 59.5 \\
\hline $\mathrm{CHF}$ & 19,661 & 38.8 & 19,521 & 57.2 & 78,220 & 54.6 \\
\hline AMI & 12,656 & 40.2 & 12,461 & 56.6 & 79,900 & 51.9 \\
\hline Asthma & 349,384 & 62.9 & 198,934 & 68.6 & 376,494 & 59.3 \\
\hline COPD & 174,932 & 52.5 & 157,279 & 64.9 & 405,258 & 56.9 \\
\hline Any mental health* & 549,347 & 67.8 & 300,793 & 70.2 & 587,783 & 59.8 \\
\hline Psychotic & 43,219 & 57.7 & 25,172 & 61.5 & 51,048 & 51.3 \\
\hline Nonpsychotic & 499,888 & 68.3 & 273,972 & 70.6 & 525,024 & 60.7 \\
\hline Substance use/other & 64,387 & 66.5 & 31,650 & 66.4 & 71,826 & 54.0 \\
\hline \multicolumn{7}{|c|}{$\mathrm{CHF}=$ congestive heart failure; $\mathrm{AMI}=$ acute myocardial infarction; $\mathrm{COPD}=$ chronic obstructive pulmonary disease. 1} \\
\hline \multicolumn{7}{|c|}{$\begin{array}{l}\text { Notes: Eligibility is defined per preventive care incentive parameters. Cervical cancer screening: women aged } 35 \text { to } 69 \text { years as of March } 31,2010 \text {, who have had a Papanico } \\
\text { laou test in the last } 30 \text { months, excluding women who have had a hysterectomy. Breast cancer screening: women aged } 50 \text { to } 69 \text { years as of March } 31,2010 \text {, who have had } \\
\text { mammogram in the last } 30 \text { months, excluding women who have had a mastectomy or are being treated for breast cancer. Colorectal cancer screening: adults aged } 50 \text { to } 74 \\
\text { years as of March 31, 2010, who have had a fecal occult blood test in the last } 30 \text { months or a colonoscopy in the past } 10 \text { years, excluding adults with known colon cancer. }\end{array}$} \\
\hline
\end{tabular}

For all 3 types of cancer screening, disparities in screening related to neighborhood income persisted over time. The ratios of the screening rates in the high- est income quintile to those in the lowest quintile for cervical, breast, and colorectal cancer, respectively, were $1.28,1.25$, and 1.36 at the start of the study period and 
Figure 1. Age- and sex-standardized cancer screening rates and annual incentive costs from 1990-2000 to 2009-2010.

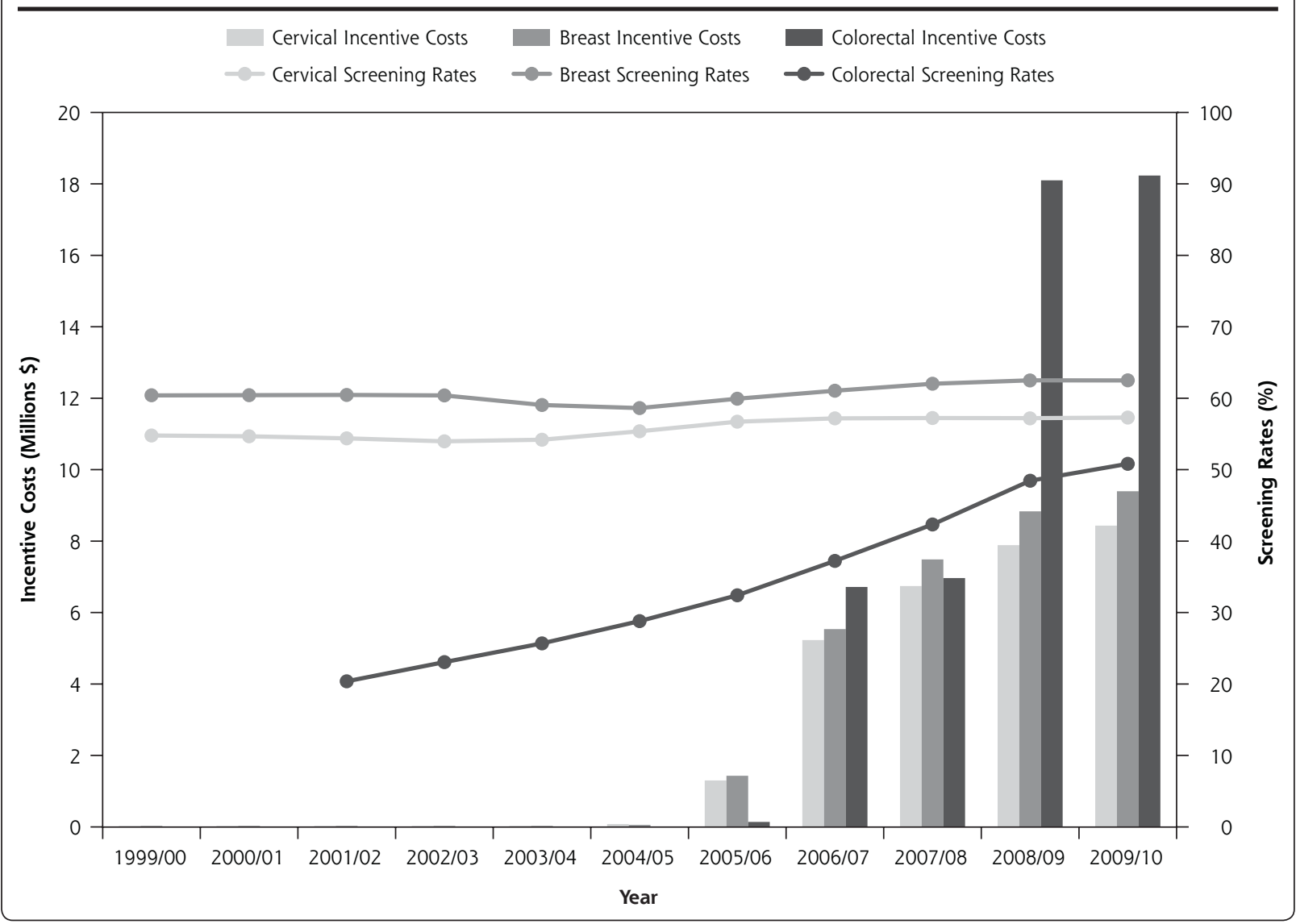

Table 3. Segmented Regression Model Parameters Showing the Year-to-Year Trend in Cancer Screening Rates Before and After Introduction of Ontario's Preventive Care Incentives In 2006-2007

\begin{tabular}{|c|c|c|c|c|c|}
\hline $\begin{array}{l}\text { Type of } \\
\text { Cancer } \\
\text { Screening }\end{array}$ & $\begin{array}{c}\text { Intercept }\left(\beta_{0}\right) \% \\
(95 \% \mathrm{Cl})\end{array}$ & $\begin{array}{c}\text { Baseline Trend } \\
\text { Before Incentives } \\
\left(\beta_{1}\right) \% \\
(95 \% \mathrm{Cl})\end{array}$ & $\begin{array}{l}\text { Step Change After } \\
\text { Introduction of } \\
\text { Incentives }\left(\beta_{2}\right) \% \\
(95 \% \mathrm{Cl})\end{array}$ & $\begin{array}{l}\text { Trend Change After } \\
\text { Introduction of } \\
\text { Incentives }\left(\beta_{3}\right) \% \\
(95 \% \mathrm{Cl})\end{array}$ & $\begin{array}{c}\text { Trend After } \\
\text { Introduction of } \\
\text { Incentives }\left(\beta_{1}+\beta_{3}\right) \% \\
(95 \% \mathrm{Cl})\end{array}$ \\
\hline \multirow[t]{2}{*}{ Cervical } & 53.9 & 0.26 & 1.5 & -0.21 & 0.045 \\
\hline & (52.5 to 55.3 ) & $(-0.054$ to 0.57$)$ & $(-0.80$ to 3.8$)$ & $(-1.0$ to 0.59$)$ & $(-0.70$ to 0.79$)$ \\
\hline \multirow[t]{2}{*}{ Breast } & 60.9 & -0.24 & 1.6 & 0.72 & 0.49 \\
\hline & (59.7 to 62.0 ) & $(-0.49$ to 0.015$)$ & $(-0.25$ to 3.5$)$ & (0.080 to 1.4$)$ & $(-0.10$ to 1.1$)$ \\
\hline \multirow[t]{2}{*}{ Colorectal } & 17.2 & 3.0 & 0.95 & 1.7 & 4.7 \\
\hline & (15.0 to 19.5$)$ & (2.3 to 3.7 ) & $(-2.2$ to 4.1$)$ & (0.55 to 2.9 ) & (3.7 to 5.7 ) \\
\hline
\end{tabular}

$1.33,1.23$, and 1.30 at the end. Individuals who were enrolled in a patient-centered medical home in 2009 had higher cancer-screening rates for all 3 types of cancer over the previous decade than those not enrolled. The ratios of the screening rates for individuals enrolled in a medical home in 2009 to the rates for those not enrolled, for cervical, breast, and colorectal cancer, respectively, were $1.46,1.40$, and 1.43 at the start of the study period and $1.96,1.77$, and 1.95 at the end.

\section{DISCUSSION}

Our findings demonstrate that the introduction of a province-wide, primary care pay-for-performance 
scheme for cervical, breast, and colorectal cancer screening was associated with little or no increase in cancer screening rates despite relatively large expenditure and very good uptake of incentives among primary care physicians. More, we found persistent disparities related to neighborhood income for all 3 types of cancer screening. Only physicians practicing in medical homes were eligible for the incentives, but individuals enrolled in a medical home were more likely to receive cancer screening than others even before introduction of the incentives.

Many factors influence the impact of financial incentives on quality of care, ${ }^{19,}{ }^{26}$ but we hypothesize that the size and structure of Ontario's incentive program played key roles in limiting its impact. The preventive care incentives were among the largest financial incentives introduced for primary care physicians in Ontario but constituted only about 3\% of their gross income. Incentives were paid directly to physicians, not to the group practices or medical homes in which they worked. By contrast, in a payfor-performance scheme for primary care physicians in the United Kingdom, incentive payments made up approximately $25 \%$ of physicians' income, were paid to the group practice, and accelerated improvements in the quality of care for some chronic diseases. ${ }^{27}$

Organizational and patient factors may also have influenced the impact of the incentives. Practices with electronic reminder systems have been shown to provide superior preventive care, ${ }^{28}$ yet only $66 \%$ of primary care physicians in Ontario reported using electronic medical records and only $37 \%$ said they could easily generate a list of patients due for preventive care..$^{29}$ Cervical and breast cancer screening rates remained relatively stable over the last decade, as they have in the United States ${ }^{30}$ and the United Kingdom, ${ }^{31}$ which may relate to some patients making an informed choice not to be screened. Other patients may need access to a female provider ${ }^{32}$ or education to address misconceptions before agreeing to be screened..$^{33}$ Small financial incentives directed to individual physicians are not likely to influence these factors.

We found that the largest improvement in screening associated with the pay-for-performance program was for colorectal cancer. This may relate to the lower baseline screening rate, the larger financial incentives, or a province-wide media campaign to promote colorectal cancer screening that launched in April 2008.

Income-related disparities in cancer screening persisted after the introduction of pay for performance. In contrast, the pay-for-performance scheme in the United Kingdom narrowed the gap in quality of care between practices serving low- and high-income populations. ${ }^{34}$ This difference may be due to the smaller size of Ontario's incentives and their limitation to physicians practicing in patient-centered medical homes, which in Ontario are less likely to serve low-income patients. ${ }^{21}$ Limiting the incentives to physicians practicing in medical homes also meant that the incentives rewarded physicians with higher baseline performance, a known pitfall of pay-for-performance schemes. ${ }^{35}$

Overall, our findings are in keeping with published systematic reviews that have found limited evidence that provider incentives increase cancer screening rates. ${ }^{17,18}$ There is, however, some evidence to support the use of other interventions, including patient or provider reminders, patient financial incentives, and organizational changes such as the adoption of standing orders for non-physician staff. ${ }^{16,17,36}$ Population-based screening programs with jurisdiction-wide coverage and centrally organized recruitment and follow-up generally have higher screening rates than programs that rely solely on individual providers or organizations. ${ }^{16}$

Our study has 2 limitations that merit emphasis. First is our reliance on administrative data. We could not include fecal occult blood tests done in public hospitals and therefore likely underestimated screening rates. This limitation likely had minimal impact on our analysis of rates over time, though. Second, our observational study could not isolate the impact of the incentives from the impact of other interventions or definitively address causation. However, because we found little or no change in screening rates after the introduction of incentives, the issue of co-intervention is less relevant. In the case of colorectal cancer screening, the province-wide media campaign introduced during the same period as the physician incentives further limits inferences about the effects of either intervention on screening rates. There were no relevant changes in guidelines during the study period.

In summary, we found that a large scale pay-forperformance scheme for primary care physicians had limited impact on cancer screening rates 3 years after its widespread introduction despite substantial expenditures. Existing income-related disparities in screening rates persisted. Incentives were largely paid to physicians who had historically higher screening rates. Policy makers should consider other strategies for improving rates of cancer screening and reducing gaps in care.

To read or post commentaries in response to this article, see it online at http://www.annfammed.org/content/12/4/317.

Key words: pay for performance; cancer screening; primary health care; delivery of health care; quality of health care

Submitted September 26, 2013; submitted, revised, February 2, 2014; accepted March 10, 2014. 
Funding support: This study was supported by the Institute for Clinical Evaluative Sciences (ICES), which is funded by an annual grant from the Ontario Ministry of Health and Long-Term Care (MOHLTC). Dr Kiran was supported as a Clinician Investigator and Dr Glazier as a Clinician Scientist by the Department of Family and Community Medicine at the University of Toronto and at St. Michael's Hospital.

Disclaimer: The opinions, results, and conclusions reported in this paper are those of the authors and are independent from the funding sources. No endorsement by ICES or the Ontario MOHLTC is intended or should be inferred.

Prior presentations: Presented, in part, at the Family Medicine Forum Research Day, Toronto, Ontario, November 14, 2012.

Acknowledgments: We would like to thank Irfan Dhalla for his comments on the manuscript.

Supplementary materials: Available at http://www.AnnFamMed. org/content/12/4/317/suppl/DC1

\section{References}

1. The National Commission on Physician Payment Reform. Report of the National Commission on Physician Payment Reform. Washington, DC; 2013.

2. The Commonwealth Fund. The Commonwealth Fund Health Care Opinion Leaders Survey: Assessing Health Care Experts' Views on Health Care Costs. New York, NY: The Commonwealth Fund; 2005.

3. Cassel CK, Jain SH. Assessing individual physician performance: does measurement suppress motivation? JAMA. 2012;307(24):2595-2596.

4. Jha AK. Time to get serious about pay for performance. JAMA. 2013; 309(4):347-348.

5. Wodchis WP, Ross JS, Detsky AS. Is P4P really FFS? JAMA. 2007;298 (15):1797-1799.

6. Kulasingam SL, Rajan R, St Pierre Y, Atwood CV, Myers ER, Franco EL. Human papillomavirus testing with Pap triage for cervical cancer prevention in Canada: a cost-effectiveness analysis. BMC Med. 2009;7(1):69.

7. Telford JJ, Levy AR, Sambrook JC, Zou D, Enns RA. The costeffectiveness of screening for colorectal cancer. CMAJ. 2010;182(12): 1307-1313.

8. Bleyer A, Welch HG. Effect of three decades of screening mammography on breast-cancer incidence. $N$ Engl J Med. 2012;367(21): 1998-2005.

9. Heath I. It is not wrong to say no. BMJ. 2009;338:b2529.

10. Welch HG. Screening mammography-a long run for a short slide? N Engl J Med. 2010;363(13):1276-1278.

11. Tonelli M, Connor Gorber S, Joffres M, et al; Canadian Task Force on Preventive Health Care. Recommendations on screening for breast cancer in average-risk women aged 40-74 years. CMAJ. 2011; 183(17):1991-2001.

12. US Preventive Services Task Force. Screening for Breast Cancer: US Preventive Services Task Force Recommendation Statement. Ann Intern Med. 2009;151(10):716-726.

13. Lofters AK, Moineddin R, Hwang SW, Glazier RH. Low rates of cervical cancer screening among urban immigrants: a populationbased study in Ontario, Canada. Med Care. 2010;48(7):611-618.

14. McGregor SE, Hilsden RJ, Li FX, Bryant HE, Murray A. Low uptake of colorectal cancer screening $3 \mathrm{yr}$ after release of national recommendations for screening. Am J Gastroenterol. 2007;102(8):1727-1735.

15. Smith RA, Cokkinides V, Eyre HJ. Cancer screening in the United States, 2007: a review of current guidelines, practices, and prospects. CA Cancer J Clin. 2007;57(2):90-104.
16. Weller DP, Campbell C. Uptake in cancer screening programmes: a priority in cancer control. Br J Cancer. 2009;101(Suppl 2):S55-S59.

17. Stone EG, Morton SC, Hulscher ME, et al. Interventions that increase use of adult immunization and cancer screening services. Ann Intern Med. 2002;136(9):641-651.

18. Town R, Kane R, Johnson P, Butler M. Economic incentives and physicians' delivery of preventive care: a systematic review. Am J Prev Med. 2005;28(2):234-240.

19. Scott A, Sivey P, Ait Ouakrim D, et al. The effect of financial incentives on the quality of health care provided by primary care physicians. Cochrane Database Syst Rev. 2011 Sep 7:(9):CD008451.

20. Glazier RH, Redelmeier DA. Building the patient-centered medical home in Ontario. JAMA. 2010;303(21):2186-2187.

21. Glazier RHZB, Rayner J. Comparison of Primary Care Models in Ontario by Demographics, Case Mix and Emergency Department Use, 2008/09 to 2009/10. ICES Investigative Report. Toronto: Institute for Clinical Evaluative Sciences; 2012.

22. Petch J, Dhalla IA, Henry DA, et al. Public payments to physicians in Ontario adjusted for overhead costs. Healthc Policy. 2012;8(2): 30-36.

23. The Johns Hopkins University. The Johns Hopkins ACG System. 2012. http://www.acg.jhsph.org/. Accessed Mar 27, 2012.

24. Wagner AK, Soumerai SB, Zhang F, Ross-Degnan D. Segmented regression analysis of interrupted time series studies in medication use research. J Clin Pharm Ther. 2002;27(4):299-309.

25. Lagarde M. How to do (or not to do) ... Assessing the impact of a policy change with routine longitudinal data. Health Policy Plan. 2012;27(1):76-83.

26. Glasziou PP, Buchan H, Del Mar C, et al. When financial incentives do more good than harm: a checklist. BMJ: British Medical Journal. 2012;345.

27. Campbell SM, Reeves D, Kontopantelis E, Sibbald B, Roland M. Effects of pay for performance on the quality of primary care in England. N Engl J Med. 2009;361(4):368-378.

28. Dahrouge $S$, Hogg WE, Russell G, et al. Impact of remuneration and organizational factors on completing preventive manoeuvres in primary care practices. CMAJ. 2012;184(2):E135-E143.

29. Health Council of Canada. How do Canadian Primary Care Physicians Rate the Health System? Results from the 2012 Commonwealth Fund International Health Policy Survey of Primary Care Physicians. Toronto: Health Council of Canada; 2013.

30. US National Institutes of Health. National Cancer Institute. Cancer trends progress report 2011/2012 update. http://progressreport. cancer.gov. Accessed Feb 5, 2013.

31. Public Health England. NHS Cancer screening programmes. http:// www.cancerscreening.nhs.uk/index.html. Accessed February 5, 2013.

32. Lofters AK, Moineddin R, Hwang SW, Glazier RH. Predictors of low cervical cancer screening among immigrant women in Ontario, Canada. BMC Womens Health. 2011;11(1):20.

33. Pham CT, McPhee SJ. Knowledge, attitudes, and practices of breast and cervical cancer screening among Vietnamese women. J Cancer Educ. 1992;7(4):305-310.

34. Doran T, Fullwood C, Kontopantelis E, Reeves D. Effect of financial incentives on inequalities in the delivery of primary clinical care in England: analysis of clinical activity indicators for the quality and outcomes framework. Lancet. 2008;372(9640):728-736.

35. Rosenthal MB, Frank RG, Li Z, Epstein AM. Early experience with pay-for-performance: from concept to practice. JAMA. 2005;294 (14):1788-1793.

36. Shekelle PG, Stone E, Maglione M, et al. Interventions that increase the utilization of Medicare-funded preventive services for persons age 65 and older. Reprints. 2003. http://www.rand.org/pubs/ reprints/RP1229. 